\title{
Ver pelo tato: contribuição do Design Inclusivo na formação de imagens mentais
}

\section{Seeing by touch: contribution of Inclusive Design in the formation of mental images}

\author{
Márcio J. S. Guimarães, Universidade Federal do Maranhão - UFMA. \\ marcio.guimaraes@ufma.br
}

\author{
Mônica Moura, Universidade Estadual Paulista - UNESP - Bauru. \\ monica.moura@unesp.br
}

\author{
Cassia Leticia Carrara Domiciano, Universidade Estadual Paulista - UNESP - \\ Bauru. \\ cassia.carrara@unesp.br
}

\begin{abstract}
Resumo
Ler e interpretar uma imagem por meio da percepção tátil é uma atividade essencial para o leitor com deficiência visual. Este artigo aborda uma reflexão sobre livros infantis, imagens táteis, sua importância para o desenvolvimento infantil e atividades de pesquisa em Design Inclusivo, visando ao desenvolvimento de materiais didáticos e paradidáticos que promovam a Educação Inclusiva. Utilizando métodos de análise qualitativa, são apresentadas duas experiências: uma de interpretação de imagens em livro inclusivo disponível no mercado editorial; outra de adaptação artesanal de materiais de apoio à leitura. Como resultado, demonstra-se possibilidades de como promover a autonomia da criança quanto à interpretação dos elementos pictóricos presentes nos livros infantis. Estas experiências foram realizadas pelos autores durante pesquisa de doutoramento em Design.
\end{abstract}

Palavras-chave: Design Inclusivo, Imagem Mental, Deficiência Visual, Livro Infantil, Contação de Histórias.

\begin{abstract}
Reading and interpreting an image through tactile perception is an essential activity for the visually impaired reader. This article treatment a reflection on children's books, tactile images, their importance for child development and research activities in Inclusive Design aimed at developing didactic and educational materials that promote Inclusive Education. Using qualitative analysis methods, two experiences are presented: one of interpreting images in an inclusive book available in the publishing market; the other of handcrafted adaptation of reading support materials. As a result, it demonstrates possibilities of how to promote the child's autonomy regarding the interpretation of pictorial elements present in children's books. These experiments were carried out by the authors during PhD research in Design.
\end{abstract}

Keywords: Inclusive Design, Mental Image, Visual Impairment, Children's Book, Storytelling. 


\section{Era uma vez...}

A aquisição da linguagem é o grande marco da transição que ocorre nos anos iniciais de vida da criança. Estes compreendem a primeira infância, isto é, do nascimento aos 6 anos de idade, caracterizada pelos desenvolvimentos físico e cognitivo, nos quais, pelas percepções dos objetos à sua volta e pela construção de seu repertório imaginativo, a criança passa a aprimorar a linguagem, a aprofundar sua comunicação com o universo exterior e a iniciar uma relação de troca de informações com adultos e com outras crianças.

É neste estágio que a contação de histórias propicia e estimula o desenvolvimento cognitivo da criança, pois, através de uma narrativa, a obtenção de conhecimento se torna mais dinâmica, novos elementos da linguagem são gradativamente internalizados e o pensamento abre espaço para novas indagações e descobertas, aguçando a criatividade e o intelecto infantil.

Histórias são contadas além da oralidade, especialmente na educação infantil. Etapa em que o meio visual assume o importante papel de estimular, complementar, reforçar e prover a manutenção dos conteúdos. Desse modo, a adaptação dos materiais com a finalidade de se tornarem inclusivos é de grande importância para a integração de todas as crianças, promovendo a inclusão e a acessibilidade às crianças com deficiência visual que, independentemente das suas restrições visuais, possuem necessidades sociais, afetivas e intelectuais próprias da infância.

O processo de Design ora apresentado se move pelo desejo de tornar possível a todas as crianças o acesso à literatura infantil, dando autonomia aos seus professores, pais ou responsáveis por meio de sugestões de como contar histórias e, assim, possibilitar, de forma adaptada, a experiência lúdica, característica dos livros infantis.

O design na contemporaneidade aponta a produção autônoma como alternativa à heteronomia. Sua presença implica a procura de projetos mais humanistas: em que o humanismo projetual se denota pelo exercício de interpretar as necessidades dos grupos sociais e elaborar propostas viáveis e emancipatórias, propiciando uma consciência crítica e abrindo espaços ao diálogo de todos os envolvidos, tornando o design participativo e integrador.

\section{Os livros com ilustrações táteis}

Livros com ilustrações táteis são recursos multissensoriais que permitem aos leitores (com e sem deficiência visual) interagir com representações pictóricas em relevo para que, através delas, possa abstrair informações que os auxilie a compreender, ampliar e/ou transmutar o conteúdo imagético que aborda a história contida em cada obra.

No Brasil, o Instituto Benjamin Constant - IBC e a Fundação Dorina Nowill - FDN ofertam a produção de livros em Braille desde a década de 1950, no entanto, a produção de livros com imagens táteis é recente: inicialmente no IBC (desde 1950), com uma produção direcionada à preparação de materiais para ensino; na FDN, ocorre desde 2008, direcionada à adaptação de livros de literatura infantil, utilizando-se do recurso gráfico de produção da imagem em relevo pontilhado. 
Na Europa, a organização francesa Le Doigts Qui Rêvent - Typhlo \& Tactus, cuja missão é aumentar a quantidade, qualidade e disponibilidade desses livros, é a principal produtora e distribuidora de livros com ilustrações táteis para crianças em idade pré-escolar.

Nos Estados Unidos da América, a American Printing House - APH e a Braille Authority North America - BANA, produzem livros e materiais didático-pedagógicos para pessoas com deficiência visual, estabelecem recomendações e ofertam cursos direcionados à produção artesanal de livros com ilustrações táteis.

No Brasil, bem como em diversos países no exterior, a produção artesanal é incentivada por três motivos principais:

1. livros com ilustrações táteis devem atender às necessidades emergentes de educação da criança com deficiência visual, desse modo, pais e professores devem elaborar livros que atendam estas necessidades específicas;

2. é desejável que os livros com ilustrações táteis sejam produzidos com materiais e cores que estejam associados às experiências culturais da criança e ao seu modo de vida, portanto, livros comerciais, especialmente os importados, podem não atender às expectativas;

3. os livros com ilustrações táteis têm um elevado custo de produção, fato que, muitas vezes, inviabiliza a produção em larga escala e onera o preço final dos produtos, tornando-os inacessíveis; a produção artesanal torna-se, portanto, uma alternativa economicamente viável.

O desenvolvimento sistemático da modalidade tátil é essencial para que a criança com deficiência visual consiga desenvolver a capacidade de organizar, transferir e abstrair conceitos das representações táteis aplicadas em livros; assim, quanto maior for a disponibilidade de materiais pedagógicos inclusivos, maior será a capacidade de desenvolvimento da formação de imagens mentais (GRIFFIN; GERBER, 1996).

\section{A formação da imagem mental}

Para que uma criança compreenda e reconheça um objeto bidimensional é desejável que primeiro ela aprenda a reconhecer o objeto concreto, sempre que possível. Uma vez armazenada a informação bidimensional que representa o objeto real, a criança passa a utilizá-la toda vez que desejar se referir graficamente àquele objeto (a formação do signo). Quanto mais cedo a criança se familiarizar com as representações do mundo real, mais cedo entenderá que o real pode ser codificado e contado por meio de elementos pictóricos e/ou táteis. Este aprendizado é essencial para que ela passe a elaborar imagens mentais. As imagens mentais são instrumentos do pensamento, utilizados como recursos de memorização, simulação mental e ferramentas de raciocínio.

Segundo Dominique Vallat \& Anne-Lise Schwab (2010, p. 97), a "imagem mental é como a pintura dos impressionistas, que interpretavam os sujeitos em vez de reproduzi-los". Sob esta vertente, infere-se que a produção de imagens mentais não é uma condição exclusiva de quem possui o sentido da visão, uma vez que os demais sentidos oferecem informações (espaciais, táteis, 
auditivas e olfativas) que permitem, mesmo à pessoa que nasceu cega, recordar-se de suas experiências de vida e constituir uma representação mental em torno de determinado conceito.

Exemplificando esta questão, acerca da simplicidade do desenho da imagem tátil, Danyele Valente (2009) expõe que durante entrevista realizada com Philippe Claudet, diretor da Editora Les Doigts Qui Rêvent - Typhlo \& Tactus, Claudet revelou que dentre o grande número de livros já produzidos pela organização, destaca-se como a obra mais bem recebida e com maior número de pedidos por instituições e escolas especializadas na educação de crianças com deficiência visual o livro Le Petit Chaperon Rouge ${ }^{I}$, originalmente planejado para o público sem deficiência, conquistou sucesso considerável com o público com deficiência visual por sua simplicidade no uso de formas e texturas.

O livro original é composto por papel acartonado, encadernado em dobra-sanfona, dispondo de um índice de personagens e cenário, cujas ilustrações foram substituídas por círculos de diferentes cores, dimensões e texturas.

A versão adaptada ao leitor com deficiência visual é composta por papel apergaminhado também encadernado em dobra-sanfona, dispondo de um índice de texturas dos personagens que, assim como no livro original, foram substituídos por círculos de diferentes cores, dimensões e texturas. A floresta em ambas as edições também é composta por círculos; no livro original é pintada em diferentes tons de verde, no livro adaptado foi impressa em relevo seco.
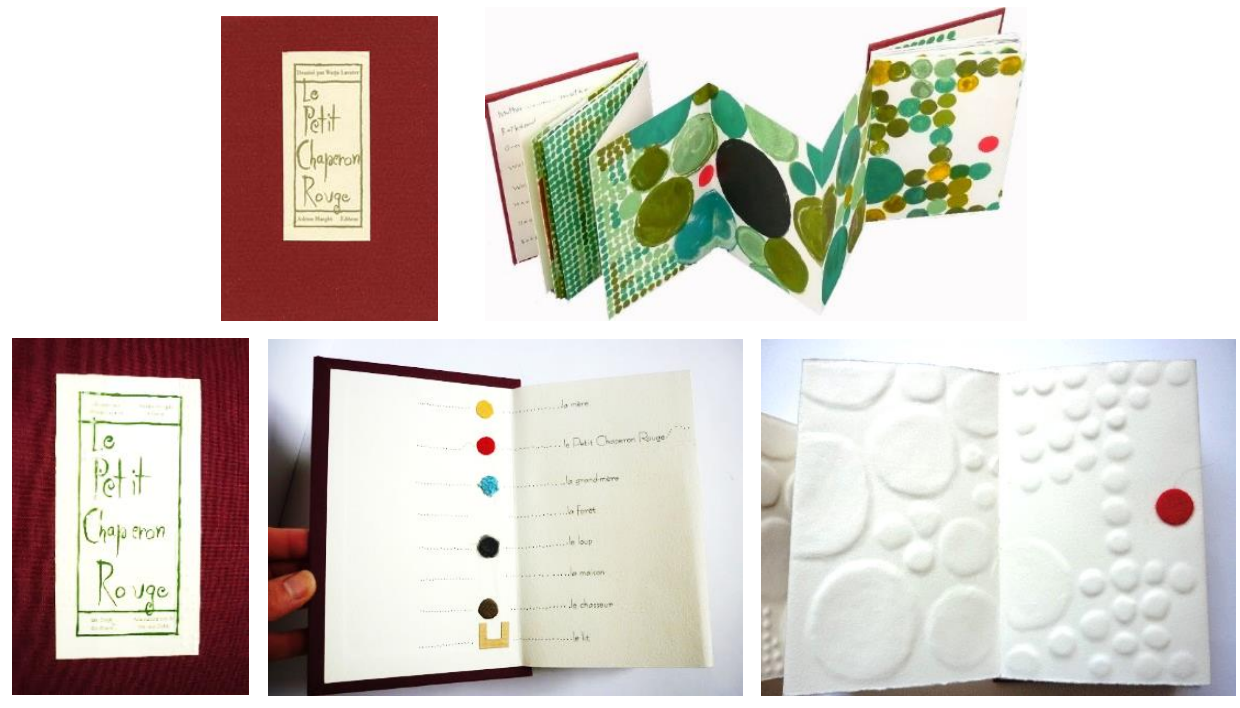

Figura 1 - Livro Le Petit Chaperon Rouge - versão original e versão tátil

Fonte: Galerie Maeght, 2018; Typhlo \&Tactus, 2018.

Descrição: a imagem, em cores, mostra a capa, o índice de texturas e a exposição do livro aberto, evidenciando o efeito das encadernações. Os personagens e elementos que compõem a narrativa foram ilustrados por círculos coloridos e/ou em relevo de diferentes tamanhos e texturas.

O acesso às ilustrações táteis favorece a formação das imagens mentais na medida em que a imagem tátil atribui um aspecto formal às representações adquiridas pelos demais sentidos, portanto, seu processo de criação exige que os profissionais responsáveis pelo planejamento e

${ }^{1}$ LAVATER, Varja; PERRAULT, Charles. Le Petit Chaperon Rouge. Paris: Editora Les Doigts Qui Rêvent - Typhlo \& Tactus, 2005. 
projeto deste tipo de material se predisponham a conhecer as modalidades perceptivas destas crianças e convivam com elas sob orientação dos profissionais que cuidam de sua educação, a fim de compreender quais os requisitos necessários ao projeto gráfico editorial.

Em pesquisa acerca da eficiência de leitura de ilustrações táteis elaboradas com a técnica de pontos em relevo similares ao ponto em sistema Braille (como as ilustrações táteis empregadas nos livros ilustrados publicados pela Fundação Dorina Nowill - FDN), realizada pelo projeto Experimentos Táteis no ano de 2016, verificou-se que, das ilustrações táteis presentes na adaptação inclusiva do livro $A$ viagem $^{2}$, muitas não eram compreensíveis.

A atividade consistiu na leitura háptica das imagens táteis e contou com a participação de 15 estudantes universitários, a saber: 4 participantes com deficiência visual (2 estudantes cegos e 2 com baixa visão) e 11 participantes sem deficiência visual (que utilizaram vendas durante a leitura).

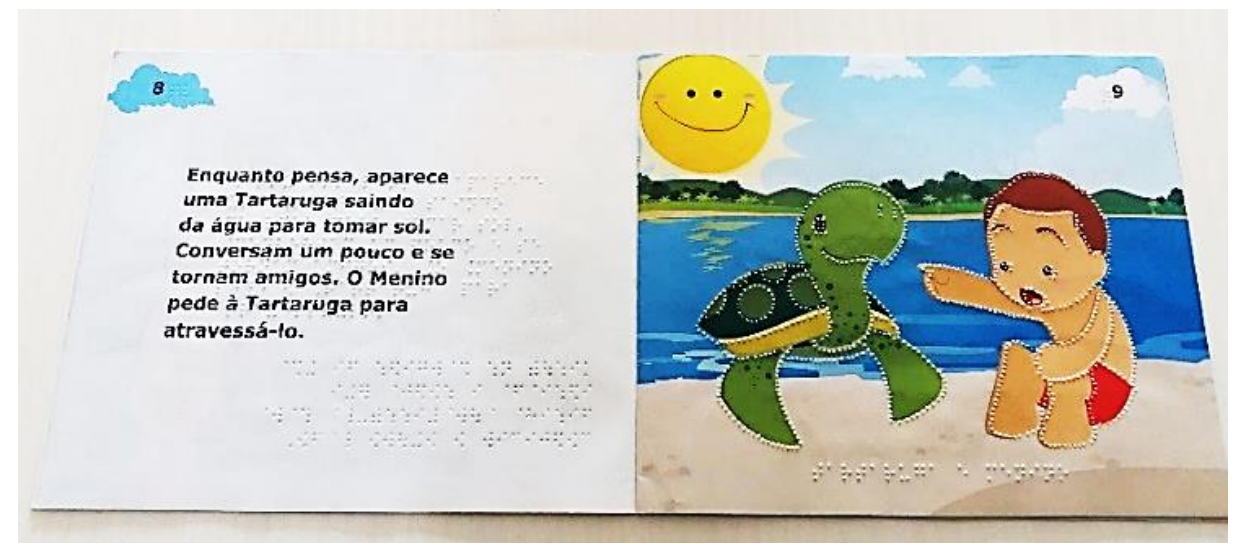

Figura 2 - Ilustração visual e tátil do livro A Viagem

Fonte: imagem produzida pelo autor, 2016.

Descrição: a imagem, em cores, mostra a ilustração de um menino sentado sobre a areia, ele conversa com uma tartaruga que está com parte do corpo submerso.

Entre os problemas observados, verificou-se que a adaptação direta da imagem elaborada para leitores sem deficiência, reproduzida pela sobreposição de pontos em relevo sobre os contornos da ilustração, desconsidera aspectos inerentes ao processo da leitura e interpretação háptica. Os resultados referentes à percepção e à interpretação da imagem, em específico (figura 2), mostraram que nenhum dos participantes reconheceu a figura da tartaruga e que grande parte deles $(75 \%)$ considerou a figura do menino como a representação do animal.

Esta experiência reitera as afirmações apontadas por Márcia Cardeal (2009) em pesquisa realizada sobre a leitura e interpretação de imagens táteis. Segundo a autora, a função háptica não é integradora como a visão e, por esta razão, não é possível à pessoa com deficiência visual a compreensão de relações espaciais (como a posição curvada do menino, seu braço esquerdo sobreposto ao desenho do corpo, as pernas dobradas etc.). Portanto, reproduzir em elementos táteis um desenho planejado para a percepção visual não atende às necessidades das pessoas cegas ou com baixa visão profunda. Em suas palavras: "a transcrição para o relevo de uma imagem

${ }^{2}$ AZEVEDO FILHO, L. A Viagem. Ilustração de Bruno Santana. Edição em Braille e fonte ampliada (FDN). Ilhéus: Editus, 2014. 
originalmente concebida para a percepção visual, sem adaptá-la à realidade perceptiva tátil, apenas corrobora a imposição de códigos visuais em nome de uma inclusão que, de fato, acaba se tornando ineficaz" (CARDEAL, 2009, p. 119).

Em análise acerca do papel das ilustrações táteis, no contexto da educação das crianças com deficiência visual, Adriano Nuernberg (2010) afirma que é necessário rever os conceitos e critérios que regem a metodologia de produção destes recursos e estes processos devem se alinhar aos esforços educacionais desenvolvidos nas escolas e instituições especializadas. O pesquisador tece críticas à adaptabilidade tátil de imagens não planejadas para tal finalidade e alerta que "a experiência perceptiva das pessoas cegas congênitas é de outra ordem", fato que "implica que suas formas de representação serão conduzidas pelos fundamentos perceptivos que lhe são próprios" (NUERNBERG, 2010, p. 135).

Para despertar o interesse da criança com deficiência visual, a imagem deve permitir que ela compreenda as partes que a formam, entenda a forma na totalidade e identifique o papel desempenhado pela imagem na narrativa. Em situação ideal, deve ainda apresentar aspectos que não necessariamente tenham sido narrados, mas complementem ou ampliem a história, permitindo que a criança abstraia de um mesmo livro muitas formas de interpretação.

Segundo Maria Nikolajeva \& Carole Scott (2011), as relações estabelecidas entre as crianças e as ilustrações ultrapassam os limites mínimos de interpretação; as crianças se adentram mais e mais nos significados por elas apreendidos, leem outras histórias. Este aspecto, da amplitude da leitura infantil, foi anteriormente apontado por Walter Benjamin em sua reflexão sobre crianças, livros e brinquedos. Nas palavras do autor:

As crianças formam o seu próprio mundo de coisas, um pequeno mundo inserido no grande. A criança consegue lidar com os conteúdos como o faz com retalhos de tecido e material de construção. Ela constrói seu mundo com os motivos do conto ou pelo menos estabelece vínculos entre os elementos do seu mundo [...] não são as coisas que saltam das páginas em direção à criança que as vai imaginando - a própria criança penetra nas coisas durante o contemplar, como nuvem que se impregna do esplendor colorido desse mundo pictórico. (BENJAMIN, 2009, p.58 e 69)

Adentrar em um livro, como expresso por estes autores, é um processo muitas vezes mediado pela imagem, especialmente na literatura infantil, categoria de livro em que a imagem seduz a criança e a convida a conhecer, reviver e/ou reinterpretar a história (que passa a ser uma nova história). Trata-se de um processo que é reconfigurado à medida que se amadurece, como afirmam Evelyn Arizpe \& Morag Styles (2004). Segundo as autoras, a leitura do livro ilustrado, realizada pela criança, se diferencia acentuadamente da leitura realizada pelo adulto, pois a grande maioria dos adultos perde a habilidade lúdica de apreciação da imagem ao ignorar a ilustração, passando a considerá-la mera decoração.

Entre os anos de 1999 e 2000, Arizpe \& Styles desenvolveram uma metodologia de análise do processo de leitura e interpretação de livros ilustrados, cujas histórias dependiam da relação mútua entre o texto verbal e o "texto pictórico". Entre os resultados levantados, as pesquisadoras identificaram diferentes níveis de aprofundamento e compreensão das imagens pelas crianças envolvidas; as crianças demonstraram grande capacidade de abstração de detalhes e subjetividades dos livros, de maneira muito superior à leitura de indivíduos adultos (ARIZPE; STYLES, 2004). 
Para Graça Ramos (2011), a capacidade de interpretar, inferir ou complementar a imagem pertence a quem a vê e como a lê, segundo seu grau de maturidade, suas vivências e fantasias. No caso da criança, agrada o jogo envolvido "entre a segurança do conhecimento e a surpresa do inusitado que os desenhos podem provocar, e este jogo se sobrepõe ao interesse pelas histórias narradas somente por palavras, que exigem imaginar todas as situações" (RAMOS, 2011, p. 19). Dessa forma, pondera-se que o desenho, quando bem elaborado, é utilizado pela criança como acesso a novos modos de interpretação.

Na obra How Picturebooks Work (2011) (traduzida no Brasil como Livro Ilustrado: Palavras e Imagens), Maria Nikolajeva e Carole Scott apresentam uma série de análises de livros ilustrados, cujas características exemplificam cada uma das categorias levantadas pelas autoras: em alguns livros ilustrados, o enredo visual é tão rico que prescinde das palavras, noutros, ao contrário, há poucas lacunas no texto verbal que possam ser desenvolvidas ou enriquecidas pelas imagens; no entanto, quando o livro apresenta redundância entre as linguagens verbal e pictórica, as imagens tornam-se relevantes.

Este problema é observado, principalmente, quando o livro não é produzido em um trabalho conjunto entre autor e ilustrador; ou quando a ilustração fica a cargo da editora - por não tomar conhecimento das ideias que serão adotadas pelo ilustrador a ser contratado, o autor tende a incluir no texto todos os detalhes que considera importantes, passando a descrever os cenários, personagens, entre outros elementos da narrativa, não deixando espaços que possam ser expandidos pela ilustração, levando o ilustrador ao desenvolvimento de uma exposição visual que se ocupa apenas de reproduzir o texto (ibidem, 2011).

Entretanto, quando autor e ilustrador atuam juntos, ou quando o autor é também o ilustrador, o livro tende a apresentar um equilíbrio entre imagem e prosa, permitindo que o leitor tenha autonomia para identificar outras histórias dentro da história. Entre os primeiros livros ilustrados pelo autor, destaca-se a obra de Beatrix Potter (1866-1943) que proporciona ao leitor a identificação de aspectos visuais que fortalece o desenvolvimento da história, mas também permite ao leitor uma atitude proativa, podendo ampliá-la a partir de elementos complementares inseridos na narrativa visual, como pode ser observado nesta ilustração de "A história de Pedro Coelho", publicado originalmente em 1902:

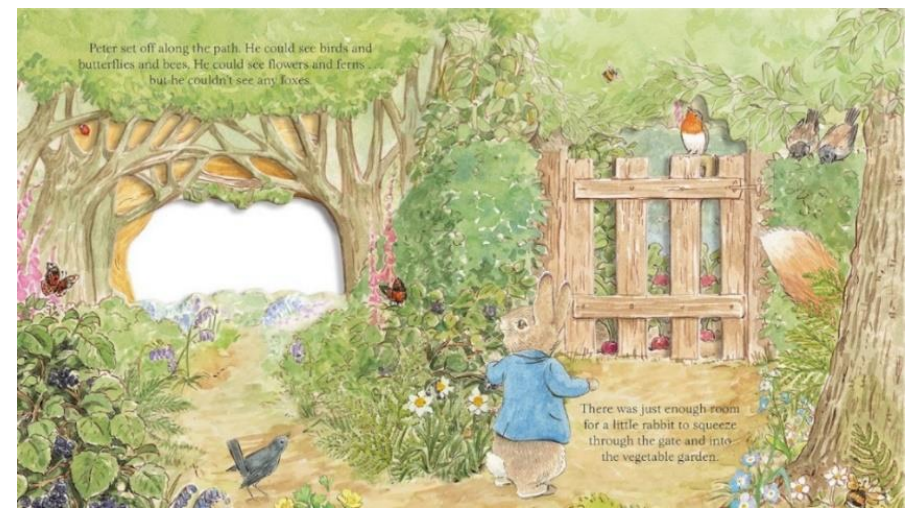

Figura 3 - A história de Pedro Coelho

Fonte: Beatrix Potter, 1902, reedição de 2009. Amazon Books UK, 2017.

Descrição: a imagem, em cores, mostra Pedro Coelho se aproximando de um portão de madeira. Ele veste uma camisa azul. Compõem o cenário o chão de terra, arbustos, flores, árvores e alguns animais e insetos que vivem na floresta, um deles escondido num arbusto. 
Considerando o papel comunicativo da imagem, Nikolajeva \& Scott (op. cit., 2004) desenvolveram uma categorização da relação envolvida entre as palavras e as imagens nos livros ilustrados.

\section{PALAVRA}

\begin{tabular}{|l|l|}
\hline Texto narrativo & Texto não narrativo \\
\hline Texto narrativo com poucas ilustrações & $\begin{array}{l}\text { Livro de lâminas (abecedário, poesia ilustrada, } \\
\text { livro com ilustração não ficcional) }\end{array}$ \\
\hline $\begin{array}{l}\text { Texto narrativo com pelo menos uma imagem } \\
\text { por página dupla (não dependente da imagem) }\end{array}$ & $\begin{array}{c}\text { Livro ilustrado simétrico } \\
\text { (duas narrativas mutuamente redundantes) }\end{array}$ \\
\hline $\begin{array}{c}\text { Livro ilustrado complementar } \\
\text { (palavra e imagem preenchem uma a lacuna da outra) }\end{array}$ \\
\hline $\begin{array}{c}\text { Livro ilustrado “expansivo" ou "reforçador" } \\
\text { (a narrativa visual apoia a verbal, a narrativa verbal depende da visual) }\end{array}$ \\
$\begin{array}{c}\text { Livro ilustrado de "contraponto" } \\
\text { (duas narrativas mutuamente dependentes) }\end{array}$ \\
$\begin{array}{c}\text { Livro ilustrado "siléptico" - com ou sem palavras } \\
\text { (duas ou mais narrativas independentes entre si) }\end{array}$ \\
\hline
\end{tabular}

\begin{tabular}{|l|l|}
\hline $\begin{array}{l}\text { Narrativas de imagens com palavras } \\
\text { (sequencial) }\end{array}$ & $\begin{array}{l}\text { Livro demonstrativo com palavras } \\
\text { (não narrativo, não sequencial) }\end{array}$ \\
\hline $\begin{array}{l}\text { Narrativa de imagens sem palavras } \\
\text { (sequencial) }\end{array}$ & $\begin{array}{l}\text { Livro demonstrativo } \\
\text { (não narrativo, não sequencial) }\end{array}$ \\
\hline Livro-imagem ou livro de imagem & \\
\hline
\end{tabular}

\section{IMAGEM}

\section{Quadro 1 - PALAVRA-IMAGEM - as categorias dos livros ilustrados}

Fonte: NIKOLAJEVA; SCOTT, 2011.

A classificação apresentada pelas autoras baseia-se na noção de iconotexto, desenvolvida por Kristin Hallberg (apud NIKOLAJEVA; SCOTT, 2011), teórica sueca que cunhou este conceito para distinguir o livro com ilustração do livro ilustrado. Segundo Hallberg, o livro ilustrado se trata de uma entidade indissociável de palavra-imagem (o iconotexto), que coopera na transmissão de uma mensagem.

A categorização proposta por Nikolajeva e Scott atinge em totalidade os livros ilustrados disponíveis no mercado, tanto impressos quanto digitais. A grande maioria dos livros ilustrados aparentemente se inclui na categoria de livros simétricos ou complementares.

Entre estes dois tipos, os livros complementares apresentam-se mais proveitosos ao desenvolvimento infantil, pois instigam a criança ao desenvolvimento de maior interação, 
agradando a crianças na primeira infância, que ainda não dominam a leitura da linguagem verbal. Esta categoria possibilita ao leitor compreender a história sem a necessidade do texto. As imagens auxiliam o leitor na identificação da narrativa verbal.

Trazendo estas discussões para o universo dos livros com ilustrações táteis acessíveis à pessoa com deficiência visual (com textos transcritos e impressos em sistema Braille, e com imagens em relevo), salienta-se que o livro simétrico (narrativa visual e verbal redundantes) pode se apresentar desnecessário quando o tema e/ou os elementos da narrativa reproduzem situações cotidianas que podem ser imaginadas ou rememoradas pelo leitor invisual - o texto já possibilita a compreensão da história.

Os livros simétricos podem provocar desinteresse no leitor, à medida que este identifica que são redundantes, passando a optar pela leitura da linguagem verbal ou pictórica. No entanto, os livros complementares (as narrativas visual e verbal preenchem uma a lacuna da outra) mostramse ideais à adaptação háptica.

Já os livros expansivos (aqueles em que a narrativa visual apoia a verbal ou a narrativa verbal depende da visual), os de contraponto (que apresentam duas narrativas mutuamente dependentes) e os silépticos (que apresentam duas ou mais narrativas independentes entre si), caracterizados pelo grande número de elementos que constituem as narrativas visuais, embora interessantes, tendem a exigir grande esforço para que se realize a interpretação háptica e a formação de imagens mentais dos elementos que os constituem.

\section{Adaptar mediante a escassez de livros inclusivos}

Como seria adaptar "A história de Pedro Coelho" ao leitor com deficiência visual?

Confeccionando artesanalmente personagens e elementos do enredo, com papel, papel maché, fazendo bonecos de pano... De inúmeras formas, mas em nenhuma delas contemplando a exploração tátil de todos os elementos que compõem a ilustração impressa, pois a percepção háptica (a percepção pelo tato), demanda que a exposição de elementos deve ser gradual: apresentando primeiramente o coelho Pedro, para, em seguida, expor os demais elementos que compõem o enredo: a vegetação para representar o bosque; a réplica de um portão como elemento representativo da casa, por exemplo.

Em uma situação ideal, a história deveria ser contada em ambiente externo, em que a criança pudesse ter contato com a natureza, com um coelho real ou mesmo um boneco produzido em material que simule a textura do animal. Desta forma, se possibilitaria à criança, por meio da percepção háptica, a percepção da forma e das características que distinguem o coelho de outros animais já conhecidos por ela, além da identificação de outros elementos da história, potencializando o aprendizado. 


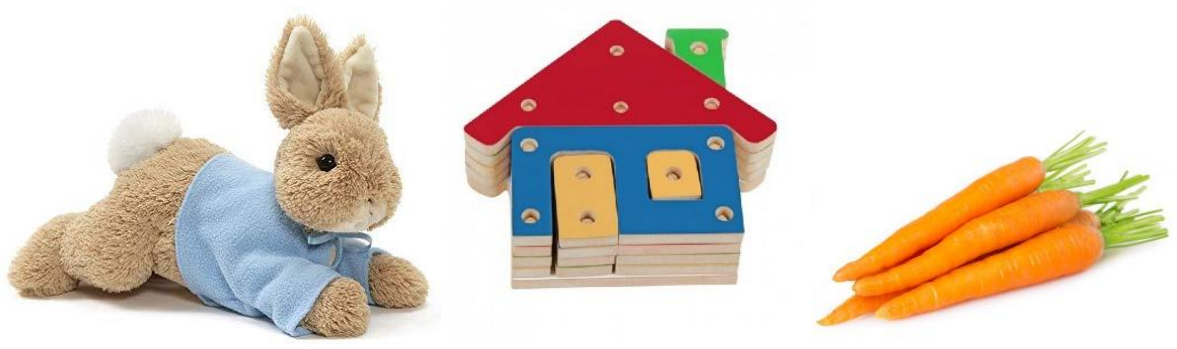

Figura 4 - Exemplos de objetos para se contar A história de Pedro Coelho

Fonte: Gund Brinquedos, Big Cérebro e iStock Photos.

\begin{abstract}
Descrição: a imagem, em cores, mostra dois brinquedos: um coelho de pelúcia usando um casaco azul e uma casa (formada pelo encaixe de peças em formatos variados, representando parede, porta, janela, telhado e chaminé); e quatro cenouras.
\end{abstract}

O uso de materiais alternativos que estimulem a percepção háptica, e, sobretudo, de objetos reais, proporcionam à criança experiências mais enriquecedoras, adequadas e necessárias à sua educação, superando o potencial ofertado por uma ilustração háptica.

Distintas pesquisas $^{3}$ apontam que a oferta da imagem tátil, por mais interessante e bem elaborada que seja, só se caracteriza como um elemento realmente essencial nos casos em que:

- o objeto a ser representado seja inacessível ao toque;

- se deseja esclarecer as relações de escala entre dois ou mais objetos;

- a imagem representa um fenômeno complexo de ser expresso em palavras, como um arco-íris, por exemplo;

- o objeto representado é frágil ou perigoso ao toque;

- quando a imagem orienta percursos, permitindo que a pessoa com deficiência visual elabore mapas mentais que a auxiliarão a deslocar-se pelos ambientes.

Quando uma história apresenta elementos que podem ser identificados por associação aos conceitos e imagens mentais já estabelecidos, a imagem tátil pode desprender-se de sua forma habitual, podendo até mesmo ser reduzida a um único elemento, desde que este elemento transmita algum aspecto sensorial que corresponda à imagem mental idealizada pela criança, como visto no caso de Le Petit Chaperon Rouge, em que todos os personagens se convertem em círculos, com cores e texturas diferenciadas.

Em nossas atividades de pesquisa, temos feito o exercício de adaptar livros infantis produzidos exclusivamente aos leitores visuais de uma maneira simples, o que tem gerado resultados promissores. Acreditamos que esta ação é uma forma de democratizar, ainda que minimamente, o acesso a livros paradidáticos infantis até então inacessíveis à criança com deficiência visual, ou que demandariam a colaboração de terceiros para a realização da leitura, promovendo autonomia.

O processo consiste na confecção manual/artesanal de cadernos com toda a parte textual do livro adaptada ao Sistema Braille, produzida com o uso de reglete e punção, acompanhados de figuras táteis (em relevo) e um boneco produzidos para uma pesquisa anterior. Estas figuras foram

${ }^{3}$ GUIMARÃES; NAKATA; MOURA, 2017; POLATO, 2013; DUARTE, 2011; entre outros. 
cortadas a laser em papel Kraft $300 \mathrm{~g} / \mathrm{m}^{2}$ e em placa acrílica de $2 \mathrm{~mm}$, como no exemplo a seguir (fig. 5):

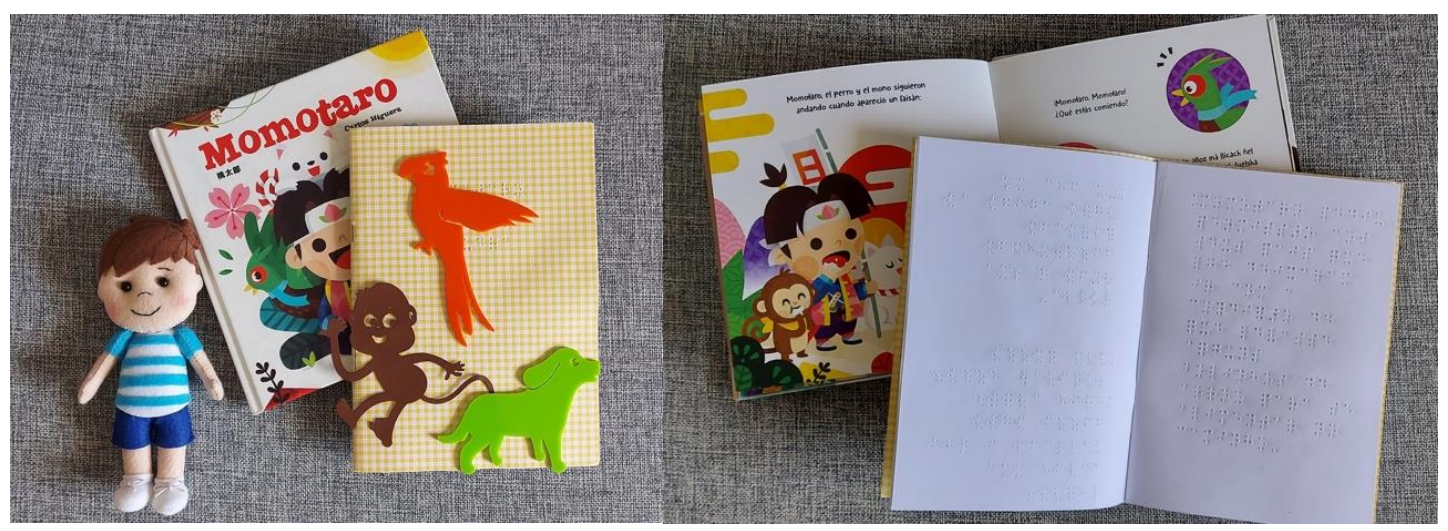

Figura 5 - Adaptação do livro Momotaro

Fonte: elaborada pelos autores.

Descrição: a imagem, em cores, mostra os materiais utilizados para a leitura tátil do livro Momotaro: um caderno com capa quadriculada nas cores amarelo e branco; o livro Momotaro (utilizado pelas professoras e crianças sem deficiência visual ou com baixa visão moderada); um boneco representando o personagem humano e três figuras bidimensionais táteis - um cachorro, um macaco e um pássaro que ajudam Momotaro em sua jornada.

Desde os primeiros meses de vida, a criança sem deficiência é estimulada a exercer sua percepção e cognição por meio da excitação proporcionada pela variedade de objetos que seu olhar alcança, independentemente de seu interesse ou da atuação de interlocutores. De modo distinto, a criança com deficiência visual necessita da estimulação oportunizada por terceiros ou ocorridas ao acaso. Tal afirmação pode, a princípio, evidenciar que o universo de experiências táteis se apresenta um tanto empobrecido quando comparado ao das experiências visuais, contudo, este quadro pode ser revertido com interesse pessoal, incentivo dos pais, dos responsáveis e professores e pela exploração ativa de recursos táteis apropriados.

O processo de estímulo à percepção háptica (a percepção pelo tato) deve ser progressivo, feito inicialmente com a utilização de objetos que caibam na mão da criança e, posteriormente, com objetos maiores que exijam movimentação e maiores articulações motoras para que se efetue a preensão tátil.

No estágio de compreensão da representação gráfica, a exploração da forma e das partes interrelacionadas dos objetos é o tipo de representação gráfica desejada. "A criança deve se familiarizar com as formas tridimensionais pelo manuseio de objetos sólidos antes de evoluir para a representação bidimensional dos objetos" (GRIFFIN; GERBER, 1996, p. 4). Uma vez que uma figura ou uma forma geométrica é reconhecida, deve ser apresentada em diversos tamanhos, permitindo que a criança possa estabelecer comparações e compreender a noção de escala, e deve ser apresentada outras vezes, possibilitando que a criança retenha a memória da forma global e estabeleça um conceito sobre a representação tátil.

Quando a percepção da figura é armazenada, a memória da representação tátil é resgatada sempre que a criança associa a esta figura ou a compara a outras figuras e formas, por isso, as representações gráficas devem ser apresentadas aos poucos, uma por vez, a fim de que a criança 
efetue estes procedimentos adequadamente, identificando os detalhes que caracterizam a figura, evitando, assim, conflitos entre as percepções de figuras que apresentam pontos semelhantes.

\section{Considerações finais}

Paulo Freire, patrono da educação brasileira, afirmava que a primeira condição para que um ser assuma um ato de comprometimento está em ser capaz de refletir e agir, estar no mundo, saber-se nele. Que compromisso não é ato passivo, mas práxis, ação e reflexão sobre a realidade. (FREIRE, 2014). Quando o designer deixa seu espaço de trabalho para ir ao encontro do outro, depara com novas perspectivas e possibilidades de projetar, ao que cabe, neste ponto, salientar outro aspecto deste contexto: o compromisso com a realidade suscita viabilidade.

A viabilidade implica conhecimento da gama de recursos disponíveis e viáveis à execução dos projetos, recursos estes que correspondem ao potencial humano, às técnicas de trabalho, insumos, maquinários e ferramentas, ao custo e ao tempo necessário.

Seria incoerente propor como resultado um produto que não condiz com a realidade de seu público, por isso, tem se tornado cada vez mais comum que os profissionais vivenciem um período de imersão junto à comunidade ou a centros de apoio e compreendam de fato suas realidades.

Por fim, acreditamos que o projeto de design do produto didático-pedagógico deve pautar-se no exercício de práticas e metodologias de desenvolvimento do produto informacional direcionado a fins educacionais inclusivos. Este processo tende a ser delineado por um percurso de descobertas e experimentações, de envolvimento com os sujeitos, de cocriação e pela compreensão de que, no âmbito da pesquisa e desenvolvimento de projeto direcionado a pessoas com necessidades específicas, o designer deve inicialmente compreender os desafios da educação inclusiva, para que possa contribuir efetivamente no processo de produzir para todos.

\section{Referências}

ARIZPE, Evelyn; STYLES, Morag. Lectura de Imágenes: los niños interpretan textos visuales. México: FCE, 2004.

BENJAMIN, Walter. Reflexões sobre a criança, o brinquedo e a educação. Tradução de Marcus Vinícius Mazzari. São Paulo: Duas Cidades Editora, 2009.

CARDEAL, Márcia. Ver com as mãos: a ilustração tátil em livros para crianças cegas. 2009. Dissertação (Mestrado em Artes Visuais) - Centro de Artes, Universidade do Estado de Santa Catarina, Florianópolis, 2009.

FREIRE, Paulo. Educação e mudança. São Paulo: Editora Paz e Terra, 2014.

GRIFFIN, Harold; GERBER, Paul. Desenvolvimento tátil e suas implicações na educação de crianças cegas. Revista do Instituto Benjamin Constant, ed. 05. Rio de Janeiro: IBC, 1996.

GUIMARÃES, Márcio; NAKATA, Milton; MOURA, Mônica. Ilustrações hápticas: imagens para a inclusão. Revista Educação Gráfica, v. 21, 3 ed., 2017.

INSTITUTO BENJAMIN CONSTANT - IBC. O processo de adaptação de livros didáticos e paradidáticos na inclusão de alunos cegos em escolas especiais e inclusivas. Revista do Instituto Benjamin Constant, Rio de Janeiro: IBC, 2008. 
NIKOLAJEVA, Maria; SCOTT, Carole. Livro ilustrado: palavras e imagens. São Paulo: CosacNaify, 2011.

NUERNBERG, Adriano. Ilustrações táteis bidimensionais em livros infantis: considerações acerca de sua construção no contexto da educação de crianças com deficiência visual.

Revista Educação Especial, v. 23, n. 36, 2010.

POLATO, Enrica. La lettura di um TIB (Tactile Illustrated Book) come contesto per l'espressione di domande da parte dei bambini com deficit visivo: uma ricerca esplorativa. Tese (Doutorado). 2013. Università degli Studi di Padova, Itália.

RAMOS, Graça. A imagem nos livros infantis: caminhos para ler o texto visual. Belo Horizonte: Autêntica Editora, 2011.

TYPHLO \& TACTUS. l'Album Illustré tátil: guidelines for books, Paris, França, 2008.

VALENTE, Danyele. Os diferentes dispositivos de imagens e ilustrações táteis e as possibilidades de produção de sentido no contexto perceptivo dos cegos. Revista Educação, Arte e Inclusão. Florianópolis, v. 02, dez. 2009.

VALLAT, Dominique; SCHWAB, Anne-Lise. Créer une bibliothèque tactile en Suisse romande pour faire face au manque de moyens d'accès à la lecture. Terra Haptica, n.1, p. 95-106, 2010.

\section{Sobre os autores}

\section{Márcio James Soares Guimarães}

Doutor em Design pela UNESP. É professor adjunto do Departamento de Desenho e Tecnologia da Universidade Federal do Maranhão e líder do grupo de pesquisa Tato Ativo: design inclusivo para a infância (CNPq/UFMA). Pratica o ensino, estudos e pesquisas com ênfase em Design Inclusivo, Design para a Educação e História do Design.

ORCID. https://orcid.org/0000-0002-3964-006X

\section{Mônica Moura}

Doutora em Comunicação e Semiótica pela PUC/SP, com Pós-doutorado em Design Contemporâneo, professora da graduação e pós-graduação em Design da Faculdade de Arquitetura, Artes, Comunicação e Design da Universidade Estadual Paulista, Campus de Bauru, coordena o Laboratório e grupo de pesquisa em Design Contemporâneo: sistemas, objetos, cultura (CNPq/UNESP). Tem experiência em design gráfico, de produto, moda, ensino e sociopolítico. ORCID. https://orcid.org/0000-0002-9994-6669

\section{Cassia Leticia Carrara Domiciano}

Doutora pela Universidade do Minho - Portugal, é Livre docente em Design Editorial pela Faculdade de Arquitetura, Artes, Comunicação e Design da Universidade Estadual Paulista Bauru, onde leciona na graduação e pós-graduação em Design e coordena o Laboratório de pesquisa e extensão Inky Design. É colíder do Grupo de Pesquisa Design Gráfico Inclusivo: visão, audição e linguagem (CNPq/UNESP). Tem experiência em design gráfico, identidade visual, produção editorial e design gráfico inclusivo.

ORCID. https://orcid.org/0000-0001-6497-2210 